American Journal of Pharmaceutical Education 2017; 81 (6) Article 109.

\title{
RESEARCH
}

\section{Experiences and Perceptions of Pharmacy Students on Practical Skills and Education During Clinical Rotations in India}

\author{
Akshaya Srikanth Bhagavathula, PharmD, ${ }^{\mathrm{a}}$ Deepak Kumar Bandari, PharmD, ${ }^{\mathrm{b}}$ Sudhir Kumar Gogikar, PharmD, \\ Asim Ahmed Elnour, $\mathrm{PhD},{ }^{\mathrm{c}}$ Abdulla Shehab, $\mathrm{PhD}^{\mathrm{c}}$ \\ ${ }^{a}$ University of Gondar-College of Medicine and Health Sciences, School of Pharmacy, Gondar, Ethiopia \\ ${ }^{\mathrm{b}}$ Vaagdevi College of Pharmacy, Telangana, India \\ ${ }^{c}$ College of Medicine and Health Sciences, UAE University, Al Ain, United Arab Emirates \\ Submitted May 30, 2016; accepted August 25, 2017; published August 2017.
}

Objective. To investigate the overall experience of pharmacy students in India during their clinical rotations and their assessment of primary mentors in imparting the intended clinical skills.

Methods. A prospective cross-sectional study using a self-administered survey instrument containing 34 items to obtain feedback from senior PharmD students in the latter three years of their six-year program from November 2014 to February 2015.

Results. Of the 415 PharmD students invited for this survey, 261(63\% response rate) completed the survey (54\% males and $46 \%$ females). Of the surveyed participants, $74 \%$ were fifth- and final-year interns undertaking clinical training in private hospitals (60.9\%). Interestingly, $37.9 \%$ of the students ranked their clinical training as "least satisfactory" and remarked that their clinical pharmacy services were not recognized or appreciated in their respective hospitals (42.9\%). However, $20 \%$ of the students expressed that their site "definitely" provided them with the opportunity to hone clinical pharmacy skills. Only $10 \%$ of the students strongly agreed that their mentors encouraged them to use resource materials and learn on their own, met with them regularly to review their work and to provide feedback, and encouraged them to express their opinion in patient-care issues.

Conclusion. Majority of PharmD students who completed the survey were "least satisfied" with their clinical training program. Mentors should take more effort to demonstrate practice-based clinical training and provide patient-centered education to PharmD students at their clinical sites.

Keywords: doctor of pharmacy, clinical pharmacy, pharmacy education, clinical skills, mentors

\section{INTRODUCTION}

Post-independence, the diploma in pharmacy (DPharm) program was the main avenue for pharmacy education in India. Pharmacists with this qualification underwent a minimum of two years of theoretical study, with a practical training period of 500 hours spread over three months in a community pharmacy or hospital. Public perceptions toward such pharmacists were poor, as the curriculum was business-oriented and lagged in patientcare. ${ }^{1}$

To make the pharmacy curriculum more patient centered, the Pharmacy Council of India (PCI) established a collaboration of institutions between Australia and India in 1996. Successively, in 1997, a master's degree in pharmacy practice was initiated by Jagadguru Sri

Corresponding Author: Deepak Kumar Bandari, Department of Pharmacy Practice, Vaagdevi College of Pharmacy, Telangana, India 506001. Tel: +91-995-165-5245. E-mail: laxmideepak.pharma@gmail.com
Shivaratreeshwara (JSS) University to train postgraduate pharmacy students in patient-directed services. ${ }^{2}$ To continue strengthening the clinical pharmacy education and practice, the pharmacy council of India (PCI) established a doctor of pharmacy (PharmD) program in 2008, consisting of five years of full-time study and one year of internship or residency, with each academic year not less than 200 working days. The curriculum consists of subjects such as pathology, pharmacology, clinical pharmacokinetics, pharmacotherapeutic drug monitoring, clinical toxicology, and pharmaceutical care. Besides theoretical subjects, in one year of internship, the students cover specialty units such as general medicine in the first six months, and any three specialties based on availability (two months each) among surgery, pediatrics, gynecology, and obstetrics, psychiatry, skin and vascular disease or orthopedics in the next six months. ${ }^{3}$

Pharmacy mentors have a crucial role in establishing a teaching and learning environment in a clinical setup. 


\section{American Journal of Pharmaceutical Education 2017; 81 (6) Article 109.}

They provide information and practical skills to enhance the knowledge and confidence of students during their clinical rotations. Today, India has guidelines on good dispensing practices for quality pharmacy services, but not for good clinical mentors for quality pharmacy education, since traditional classroom-based teaching approaches are more common.

To date, no established board or authority in India has assessed the feedback of clinical pharmacy students toward theoretical and practical teaching techniques of their mentors. Likewise, there is no continuous evaluation of knowledge and practical skills of mentors at clinical sites, a crucial factor for delivering quality education and developing a strong and effective clinical pharmacy workforce in India. This study aimed to investigate the overall clinical experience of PharmD students during their clinical rotations and evaluate their mentors' abilities to provide them with the intended clinical skills. It emphasizes the need to constitute a body at central or state level for maintaining a database of mentors updated with routine feedback from the students.

\section{METHODS}

A prospective cross-sectional study was conducted using survey instruments to obtain feedback from PharmD students regarding their clinical experiences and the ability of their primary mentors in effectively honing their practical skills in the clinic to meet the goals of the curriculum.

Senior PharmD students from the fourth, fifth and sixth years in the program undertaking experiential clinical rotations in hospitals from 72 institutions located in north and south India were invited to participate in the study from November 2014 to February 2015. To assess the quality of practical skills taught to PharmD students, an evaluation approach was used to assess the impact of the clinical rotation experiences on student learning. The PharmD syllabus is a practical, experience-based learning process designed to hone clinical pharmacy competencies necessary to practice pharmaceutical care by engaging students in direct patient care under the supervision of experienced mentors. The students were expected to assess the patients' drug-related needs and manage those needs through appropriate interventions, education, monitoring, rational therapeutic plan, and follow-up care. Students were required to participate in a variety of direct and indirect patient care activities to take on such responsibilities. ${ }^{4}$

The main focus of these clinical rotations is to provide students with practical knowledge and clinical skills about PC and experience collaborating with other health care teams in various clinical wards. Clinical rotations provide opportunities for students to assist PC services in various pharmacy practice sites under the supervision of expert mentors. Further, mentors guide them to build the patient-pharmacist relationship and ensure positive working experience with interdisciplinary health care teams in the clinical decision-making processes. ${ }^{5}$

PharmD students are posted in various clinical wards for a period of 50-200 hours during their academic years in the program. In the fifth year, students spend half a day (in the morning) attending daily ward rounds as part of their clerkship. During the sixth year, students undergo an intensive mandatory rotational internship. They are expected to conduct pharmacy practice, acquire wet skills under supervision and function independently. During this period, students are expected to provide patient care in cooperation with the interprofessional health care team; use evidence-based medical resources to improve therapeutic outcome of medication use; promote health improvement, wellness, and disease prevention in cooperation with patients and professional health care providers; demonstrate sound therapeutic skills in monitoring and provide clinical pharmacy services for positive therapeutic outcome of the patients; and communicate effectively with patients and professional health care providers. $^{3}$

A self-administered survey was used for this study. The survey was based on a previous study ${ }^{6}$ on community pharmacy students with modifications to suit the study settings. The draft survey was distributed to 10 randomly selected faculty members to assess the readability and validity before pretesting among 20 randomly selected PharmD students for clarity, relevance, and acceptability. Refinements were made to facilitate better comprehension and question organization before the final survey was distributed among the study population. Senior PharmD students from the fourth, fifth and sixth years of the program undertaking mandatory clinical rotations were requested to complete the questionnaire. No financial incentives were provided to the study participants, who were encouraged to participate voluntarily.

The final structured survey questionnaire consisted of five sections with a total of 34 items, consisting of the sociodemographic characteristics of the students (eight items); overall satisfaction about their clinical training program and recognition of their services in clinical sites (two items); commonly identified drug-related problems during their clinical rotations (one item); student experience at their clinical sites (13 items); and student evaluation of their primary mentors' abilities to provide them with the intended experiences (10 items). 


\section{American Journal of Pharmaceutical Education 2017; 81 (6) Article 109.}

Sociodemographic characteristics included gender, age, marital status, year of study in the program, type of hospital and bed capacity, number of clinical mentors in the institution, and qualification of the primary mentor. The students' overall satisfaction of the provided clinical training program was assessed using a 4-point Likert scale $(1=$ least satisfied to $4=$ highly satisfied $)$ and recognition of clinical pharmacy services at their clinical sites, with a 5 -point Likert scale ranging from $5=$ highly accepted to $1=$ not accepted. One question was related to identifying common drug-related problems in wards, and encouraged participants to select up to three options out of 10 available options.

To assess the extent to which clinical sites provided opportunities to achieve competent PharmD goals, a 13-item questionnaire listing specific goals with a 4-point Likert scale $(4=$ definitely occurred, $3=$ partially occurred, $2=$ did not occur, $1=$ not applicable) was utilized. Further, 10 items asked students to evaluate their primary mentor in his or her ability to provide them with the intended experiences by means of a 5-point Likert scale ( 1 =not applicable, $2=$ strongly disagree, $3=$ moderately disagree, $4=$ moderately agree, and $5=$ strongly agree). The evaluation included questions on the availability of mentors in the wards, adequate orientation, and opportunities to engage in all mandatory activities included in the PharmD curriculum, regular meetings, bedside teaching, and an effective patient-centered education.

Ethical approval was obtained through the Mahatma Gandhi Memorial Hospital (MGM), Warangal, Telangana State, India.

Data from the completed survey were entered in Microsoft Excel 2007 (Redmond, WA) and analyzed using Statistical Package for Social Science (SPSS) Version 22 (Chicago, IL). Sociodemographic characteristics were summarized as descriptive statistics and inferential analysis. The percentages were computed for all the survey statements (Tables 2 and 3). Correlation between students' experiences and mentor skills was determined by using multiple logistic regressions. In all statistical analyses, a $p$ value of $\leq .001$ was considered to be statistically significant.

\section{RESULTS}

A total of 415 senior PharmD students were invited to take the survey; 261 completed the survey. The overall response rate was $63 \%$.

Among the surveyed student population, 54\% were males, and $46 \%$ were females with a mean age of 23.5 (.5). Most were single (97\%), and $74 \%$ were in their fifth and final year of the PharmD program. Majority of the students $(87 \%)$ reported that an average of four to six clinical mentors were present in their institution, with the most common qualification of the primary mentor being the master's degree of pharmacy practice $(61 \%)$. Many $(61 \%)$ were undertaking clinical attachments in private hospitals with a bed capacity of $\leq 300(63.2 \%)$ (Table 1).

When asked about their overall satisfaction with the clinical training program, $37.9 \%$ of students expressed that they were least satisfied, and $42.5 \%$ said their clinical pharmacy services were not recognized in their hospitals (Figures 1, 2).

During their clinical rotations, the most commonly identified and reported drug-related problems in the wards included unnecessary drug therapy $(78.2 \%)$, adverse drug reactions $(39.1 \%)$, non-adherence $(35.2 \%)$, ineffective therapy $(33.7 \%)$, and drug-drug interactions (29.1\%), respectively (Figure 3 ).

Table 1. Sociodemographic Characteristics of the Study Participants ( $\mathrm{N}=261)$

\begin{tabular}{lcc}
\hline Variables & Number (n) & Percentage (\%) \\
\hline Gender & & \\
Male & 140 & 54 \\
Female & 121 & 46 \\
Age & & \\
$18-21$ & 67 & 26 \\
$22-25$ & 190 & 73 \\
$26-29$ & 1 & .4 \\
$\geq 30$ & 3 & 1.1 \\
Marital Status & & \\
Single & 253 & 97 \\
Married & 8 & 3 \\
Current PharmD Year & & \\
Fourth Year & 68 & 26 \\
Fifth Year & 102 & 39 \\
Internship/Residency & 91 & 35 \\
Type of Hospital & & \\
Government & 90 & 5 \\
Semi-government & 12 & 5 \\
Private & 159 & 61 \\
Hospital Bed Capacity & & \\
$\quad 300$ Beds & 165 & 63 \\
>300 Beds & 96 & 37 \\
Number of Clinical Mentors & & \\
1-3 & 22 & 90 \\
4-6 & 227 & 87 \\
>6 & 12 & 5 \\
Primary Mentor Qualification & & \\
MPharm & 159 & 61 \\
PharmD & 93 & 36 \\
PhD & 9 & 3 \\
\hline & & \\
\hline
\end{tabular}




\section{American Journal of Pharmaceutical Education 2017; 81 (6) Article 109.}

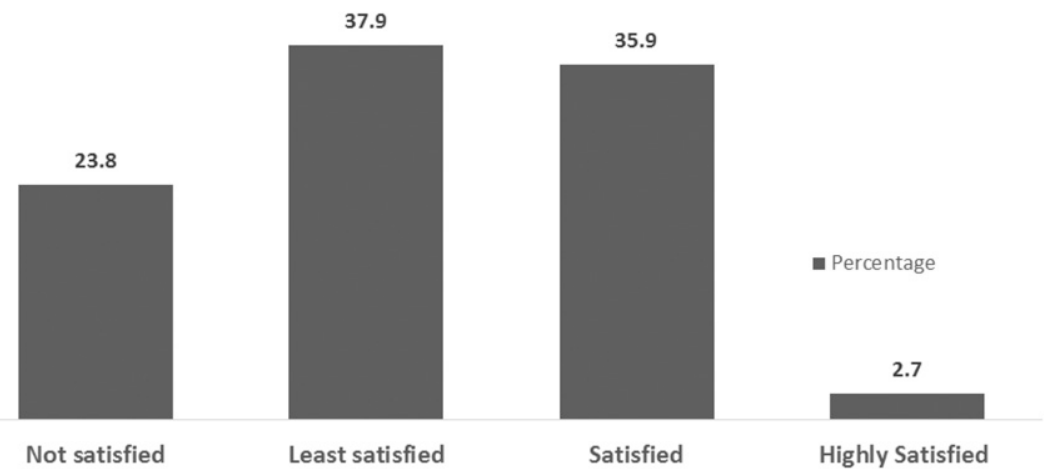

Figure 1. Satisfaction of PharmD students on clinical training provided $(\mathrm{N}=261)$.

The student evaluations of clinical training sites are summarized in Table 2. One-third of the students said that their site "definitely" provided them opportunities to develop professional maturity and responsibility (34.9\%); therapeutic and disease knowledge (31.8\%); skills related to communication $(30.3 \%)$; ability to interview patients (26.8\%); and allowed them to interact with patients and other health care providers to improve their clinical skills and confidence $(23.4 \%)$. However, $39 \%$ to $51 \%$ of the students stated that their clinical sites did not provide them with sufficient opportunity to hone skills essential for providing pharmaceutical care. Activities such as interviewing patients $(51 \%)$, identifying and resolving drug-related problems $(44.4 \%)$, refining communication skills $(43.3 \%)$, overcoming barriers to provide pharmaceutical care (43.3\%) and engaging in activities that improved their clinical skills $(39.5 \%)$ were reported as "partially occurred." Further, more than one-third of the students reported that expanding their understanding and application of pharmaceutical care (41.4\%), documenting their interventions for drug-related problems identified (35.6\%), interacting with patients and other health care providers to improve clinical skills (35.2\%), prioritizing drug-related problems $(34.9 \%)$, and accessing patient records (34.5\%) had "not occurred" during their clinical rotations (Table 2).

When evaluating their mentors (Table 3), $14.6 \%$ of students strongly agreed that their mentor encouraged them to use resource materials and learn on their own, met with them regularly to review their work and provide feedback (11.5\%), and encouraged them to express opinion on patient care issues (11.5\%). However, $31.1 \%$ of students moderately agreed that their mentor provided them with an adequate orientation, the opportunity to engage them in all of the mandatory activities, provided them with clear instructions before entering clinical sites, and involved them in discussions and problem-solving at the bedside. Students strongly disagreed when asked if their mentors were readily available in the ward to answer their queries $(42.1 \%)$, provided patient-centered education effectively (40.6\%), and participated in active discussion and problem-solving by the bedside (38.7\%).

The $p$ values for correlation between opinions on clinical training opportunities and mentors are summarized in Table 4. Significant positive correlation was noted between statements. Professional maturity and responsibility was found to have a significant association with communication skills $(p<.001)$, engagement in all

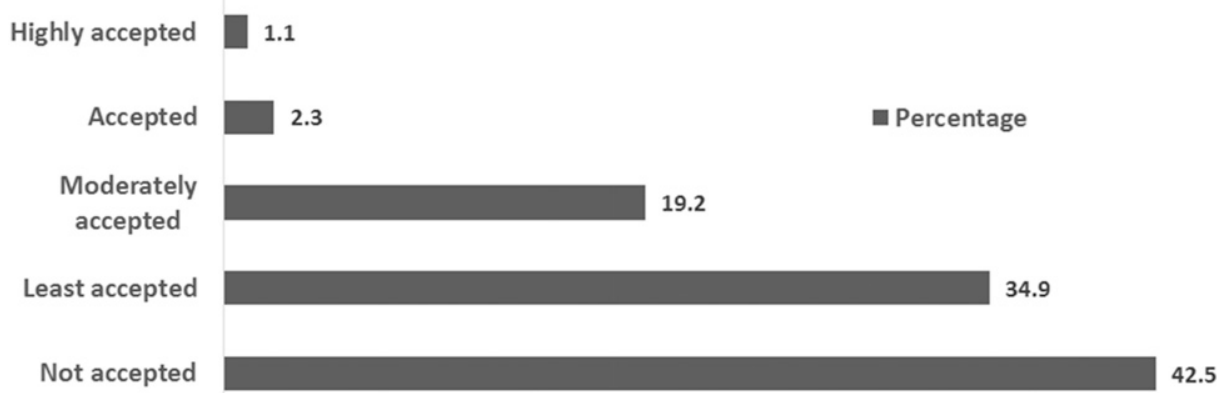

Figure 2. Student opinions on acceptance of clinical pharmacy services in their hospitals $(\mathrm{N}=261)$. 


\section{American Journal of Pharmaceutical Education 2017; 81 (6) Article 109.}

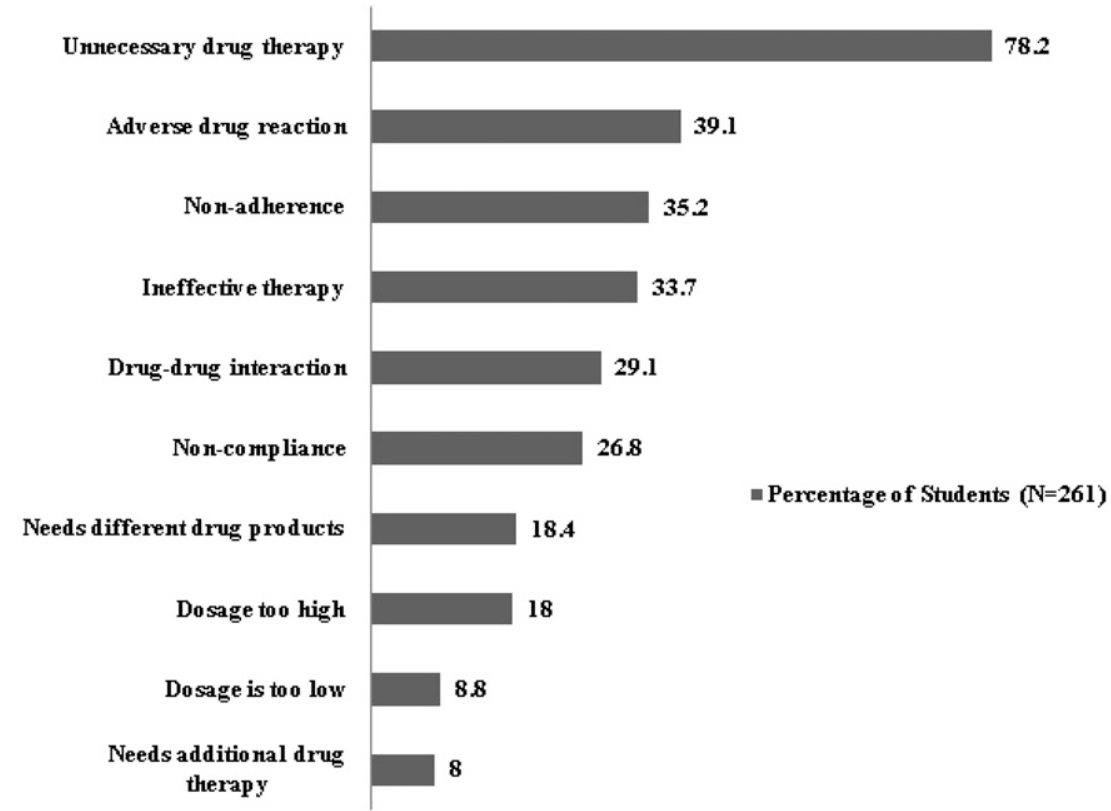

Figure 3. Most Identified Drug-Related Problems by Students and Their Responses $(\mathrm{N}=261)$.

mandatory clinical activities $(p<.001)$, therapeutic knowledge and disease process $(p<.001)$ and ability to interview a patient $(p<.001)$. In addition, significant association was found between statements; mentor meeting the students regularly with professional maturity and responsibility $(p<.001)$ was associated with communication skills $(p<.01)$, adequate clinical orientation $(p<.001)$, readily available to answer questions in wards

Table 2. Opinions of PharmD Students on Clinical Training Opportunities Received $(\mathrm{N}=261)$

\begin{tabular}{|c|c|c|c|c|c|}
\hline & \multirow[b]{2}{*}{ Statement } & \multicolumn{4}{|c|}{$\begin{array}{l}\text { Extent of which these occurred } \\
\qquad N=261(\%)^{\mathrm{a}}\end{array}$} \\
\hline & & $\begin{array}{l}\text { DO } \\
\text { n (\%) }\end{array}$ & $\begin{array}{c}\text { PO } \\
\text { n }(\%)\end{array}$ & $\begin{array}{c}\text { NO } \\
\text { n }(\%)\end{array}$ & $\begin{array}{c}\text { NA } \\
\text { n }(\%)\end{array}$ \\
\hline $\mathrm{C} 1$ & Develop professional maturity and responsibility to contribute to patient care. & $91(34.9)$ & $103(39.5)$ & $62(23.8)$ & $5(1.9)$ \\
\hline $\mathrm{C} 2$ & $\begin{array}{l}\text { Develop communication skills to establish pharmacist-patient therapeutic } \\
\text { relationship and empathy. }\end{array}$ & $79(30.3)$ & $113(43.3)$ & $66(25.3)$ & $3(1.1)$ \\
\hline C3 & Develop ability to interview patients to obtain relevant information. & $70(26.8)$ & $133(51.0)$ & $40(15.3)$ & $18(6.9)$ \\
\hline $\mathrm{C} 4$ & $\begin{array}{l}\text { Develop problem solving skills to assess patient's drug therapy and } \\
\text { medical conditions to identify drug-related problems. }\end{array}$ & $54(20.7)$ & $116(44.4)$ & $84(32.2)$ & $7(2.7)$ \\
\hline $\mathrm{C} 5$ & $\begin{array}{l}\text { Develop ability to prioritize the identified drug-related problems in the } \\
\text { order to be addressed. }\end{array}$ & $58(22.2)$ & $102(39.1)$ & $91(34.9)$ & $10(3.8)$ \\
\hline C6 & $\begin{array}{l}\text { Integrate the theoretical aspects learned in the PharmD program for the } \\
\text { assessment and resolution of drug therapy problems. }\end{array}$ & $52(19.9)$ & $120(46.0)$ & $79(30.3)$ & $10(3.8)$ \\
\hline $\mathrm{C} 7$ & $\begin{array}{l}\text { Develop documentation skills using pharmaceutical care plans, including the } \\
\text { drug-related problem, recommendations, monitoring plans and follow-up. }\end{array}$ & $47(18.0)$ & $110(42.1)$ & $93(35.6)$ & $11(4.2)$ \\
\hline C8 & Develop growing knowledge base of disease processes and therapies. & $83(31.8)$ & $111(42.5)$ & $58(22.2)$ & $9(3.4)$ \\
\hline C9 & Develop inter-professional communication skills and working relationship. & $38(14.6)$ & $137(52.5)$ & $79(30.3)$ & $7(2.7)$ \\
\hline $\mathrm{C} 10$ & Expand exposure to patient records and their utilization to provide care. & $56(21.5)$ & $107(41.0)$ & $90(34.5)$ & $8(3.1)$ \\
\hline $\mathrm{C} 11$ & $\begin{array}{l}\text { Expand understanding of real and perceived barriers to providing } \\
\text { pharmaceutical care in practice and how these may be overcome. }\end{array}$ & $29(11.1)$ & $113(43.3)$ & $108(41.4)$ & $11(4.2)$ \\
\hline $\mathrm{C} 12$ & $\begin{array}{l}\text { Ample opportunity to interact with patients and health care providers to } \\
\text { improve clinical skills and confidence. }\end{array}$ & $61(23.4)$ & $103(39.5)$ & $92(35.2)$ & $5(1.9)$ \\
\hline $\mathrm{C} 13$ & Participate in ward rounds along with mentors regularly. & $56(21.5)$ & $110(42.1)$ & $82(31.4)$ & $13(5.0)$ \\
\hline
\end{tabular}

${ }^{\mathrm{a}} \mathrm{DO}=$ definitely occurred; $\mathrm{PO}=$ partially occurred; $\mathrm{NO}=$ did not occur; $\mathrm{NA}=$ not applicable $\mathrm{n}=$ number of respondents 


\section{American Journal of Pharmaceutical Education 2017; 81 (6) Article 109.}

Table 3. Opinions of PharmD Students of Their Mentors $(\mathrm{N}=261)$

\begin{tabular}{|c|c|c|c|c|c|c|}
\hline & \multirow[b]{2}{*}{$\begin{array}{l}\text { Evaluate your primary mentor for the } \\
\text { following criteria }\end{array}$} & \multicolumn{5}{|c|}{ Extent these criteria occurred $^{\mathrm{a}}$} \\
\hline & & $\begin{array}{c}\text { SA } \\
\text { n }(\%)\end{array}$ & $\begin{array}{c}\text { MA } \\
\text { n (\%) }\end{array}$ & $\begin{array}{c}\text { MD } \\
\text { n }(\%)\end{array}$ & $\begin{array}{c}\text { SD } \\
\text { n }(\%)\end{array}$ & $\begin{array}{l}\text { NA } \\
\text { n }(\%)\end{array}$ \\
\hline P1 & $\begin{array}{l}\text { Provided adequate orientation, including clinical } \\
\text { setting expectations, introduction to ward staff, } \\
\text { review of student's learning process. }\end{array}$ & $29(11.1)$ & $136(52.1)$ & $42(16.1)$ & $51(19.5)$ & $3(1.1)$ \\
\hline $\mathrm{P} 2$ & $\begin{array}{l}\text { Provided opportunities to engage in all mandatory } \\
\text { curricular activities. }\end{array}$ & $18(6.9)$ & $98(37.5)$ & $57(21.8)$ & $66(25.3)$ & $22(8.4)$ \\
\hline P3 & $\begin{array}{l}\text { Met with students regularly to review work, provide } \\
\text { direction and feedback. }\end{array}$ & $30(11.5)$ & $90(34.5)$ & $68(26.1)$ & $62(23.8)$ & $11(4.2)$ \\
\hline P4 & $\begin{array}{l}\text { Gave clear instructions to students before entering } \\
\text { clinical rotation sites. }\end{array}$ & $11(4.2)$ & $95(36.4)$ & $90(34.5)$ & $61(23.4)$ & $4(1.5)$ \\
\hline P5 & $\begin{array}{l}\text { Involved students in active discussions and problem } \\
\text { solving by the bedside. }\end{array}$ & $29(11.1)$ & $62(23.8)$ & $52(19.9)$ & $101(38.7)$ & $17(6.5)$ \\
\hline P6 & Was readily available to answer questions in wards. & $23(8.8)$ & $48(18.4)$ & $61(23.4)$ & $110(42.1)$ & $19(7.3)$ \\
\hline P7 & Demonstrated pharmaceutical care processes effectively. & $25(9.6)$ & $65(24.9)$ & $92(35.2)$ & $65(24.9)$ & $14(5.4)$ \\
\hline P8 & $\begin{array}{l}\text { Encouraged students to use resource materials and } \\
\text { learn on their own. }\end{array}$ & $38(14.6)$ & $78(29.9)$ & $70(26.8)$ & $68(26.1)$ & $7(2.7)$ \\
\hline P9 & $\begin{array}{l}\text { Encouraged students to express opinions in patient } \\
\text { drug-therapeutic issues. }\end{array}$ & $30(11.5)$ & $92(35.2)$ & $73(28.0)$ & $63(24.1)$ & $3(1.1)$ \\
\hline $\mathrm{P} 10$ & Provided patient-centered education effectively. & $24(9.2)$ & $75(28.7)$ & $41(15.7)$ & $106(40.6)$ & $15(5.7)$ \\
\hline
\end{tabular}

${ }^{a} \mathrm{SA}=$ strongly agree, $\mathrm{MA}=$ moderately agree, $\mathrm{MD}=$ moderately disagree, $\mathrm{SD}=$ strongly disagree, $\mathrm{NA}=$ not applicable

$\mathrm{n}=$ number of respondents

$(p<.001)$ and providing effective patient-centered education $(p<.001)$ (Table 4$)$.

\section{DISCUSSION}

This study aimed to understand the clinical experiences of PharmD students in India and the extent of their mentors' teaching skills. When students were asked to rate their overall clinical training and recognition of their services in their hospital, nearly $40 \%$ of them indicated that they were "least satisfied" with the training provided, and only $2.3 \%$ of their clinical pharmacy services were accepted. These observations highlight that PharmD students are not getting sufficient exposure to clinical training and reflect the lack of awareness regarding clinical pharmacy services in Indian hospitals. This is unfortunate, because the profession of pharmacy practice is evolving slowly in India. Hence, the implementation of the PharmD program must largely emphasize on bringing awareness among health professionals about the importance of clinical pharmacy services in patient outcomes, especially in the areas of patient care encompassing PC. ${ }^{7}$

One-third of students reported that they "definitely" received opportunities to develop professional maturity and responsibility, therapeutic and disease knowledge, skills related to communication and interviewing patients. When asked to evaluate if their mentor involved them adequately, approximately half of the students moderately agreed and one out of five strongly disagreed with this statement. Thus, overall, the newly implemented PharmD program in India falls short of providing students with an adequate clinical orientation required to develop clinical pharmacy competencies. However, Western pharmacy institutes that have implemented PharmD programs are producing well-trained clinical pharmacists equipped with all of the essential clinical skills and knowledge. ${ }^{8}$ Training of mentors in problem-based learning techniques may help them to produce competent clinical pharmacists and achieve patient care goals.

The PharmD program was started in India in 2008 with the intention of producing more clinically oriented pharmacists by providing them with experiential patientcentered education effectively. In our study, only less than $15 \%$ ranked their clinical experiences favorably. One possible explanation is that clinical pharmacy is still in its developmental stages in India, and PharmD students may face obstacles in seeking support from health professionals. Additional issues include the lack of skillful mentors with exposure and training to pharmaceutical care, lack of coordination between the hospitals and pharmacy colleges, and the public perception of pharmacy practitioners in hospital pharmacy practice in India as that of "compounders" and "dispensers." Indeed, the tradition of clinical pharmacy activities is at a nascent stage and 
American Journal of Pharmaceutical Education 2017; 81 (6) Article 109.

Table 4. Factors Associated With Student Responses on Clinical Sites and Mentoring Skills

\begin{tabular}{|c|c|c|c|c|c|c|c|c|c|c|c|}
\hline No. & Statements & P1 & P2 & P3 & P4 & P5 & P6 & P7 & P8 & P9 & P10 \\
\hline $\mathrm{C1}$ & $\begin{array}{l}\text { Develop professional maturity and responsibility to } \\
\text { contribute to patient care. }\end{array}$ & .005 & .083 & .000 & .004 & .148. & .335 & .003 & .025 & .015 & .001 \\
\hline C2 & $\begin{array}{l}\text { Develop communication skills to establish the } \\
\text { pharmacist-patient therapeutic relationship and } \\
\text { empathy. }\end{array}$ & .000 & .005 & .000 & .000 & .609 & .330 & .000 & .000 & .000 & .000 \\
\hline C3 & $\begin{array}{l}\text { Develop ability to interview patients to obtain } \\
\text { relevant information. }\end{array}$ & .007 & .102 & .001 & .402 & .765 & .246 & .376 & .000 & .420 & .810 \\
\hline C4 & $\begin{array}{l}\text { Develop problem solving skills to assess patient's } \\
\text { drug therapy and medical conditions, to identify } \\
\text { drug-related problems. }\end{array}$ & .099 & .567 & .001 & .025 & 203 & .001 & .001 & .416 & .001 & .000 \\
\hline C5 & $\begin{array}{l}\text { Develop ability to prioritize the identifi } \\
\text { problems in the order to be addresse }\end{array}$ & .002 & .000 & .003 & .010 & .653 & .220 & .080 & .000 & .025 & .095 \\
\hline C6 & $\begin{array}{l}\text { Integrate the theoretical aspects learned in the } \\
\text { clinical pharmacy program for the assessment } \\
\text { and resolution of drug therapy problems. }\end{array}$ & .002 & .000 & .029. & .084 & .771 & .928 & .008 & .000 & .000 & .001 \\
\hline C7 & $\begin{array}{l}\text { Develop documentation skills using pharmaceutical } \\
\text { care plans, including the drug-related problem, } \\
\text { recommendations, monitoring plans and follow-up. }\end{array}$ & .000 & .590 & .002 & .108 & .889 & .000 & .001 & .001 & .067 & .005 \\
\hline C8 & $\begin{array}{l}\text { Develop growing knowledge base of disease processes } \\
\text { and therapies. }\end{array}$ & .154 & .769 & .000 & .000 & .541 & .002 & .000 & .031 & .021 & .002 \\
\hline C9 & $\begin{array}{l}\text { Develop inter-professional communication and } \\
\text { working relationship. }\end{array}$ & .016 & .310 & .001 & .000 & .235 & .029 & .528 & .010 & .004 & .001 \\
\hline C10 & $\begin{array}{l}\text { Expanded exposure to patient records and their } \\
\text { utilization to provide care. }\end{array}$ & .010 & .000 & .004 & .000 & .070 & .593 & .005 & .000 & .001 & .045 \\
\hline C11 & $\begin{array}{l}\text { Expand understanding of real and perceived barriers } \\
\text { to providing pharmaceutical care in practice and } \\
\text { how these may be overcome. }\end{array}$ & .056 & .001 & .002 & .000 & .001 & .537 & .000 & .000 & .001 & .000 \\
\hline C12 & $\begin{array}{l}\text { Give ample opportunity to interact with patients and } \\
\text { health care providers to improve clinical skills and } \\
\text { confidence. }\end{array}$ & .002 & 497 & .000 & .000 & .039. & .000 & .000 & .009 & .001 & .000 \\
\hline C13 & Participate in ward rounds along with mentors regularly. & .000 & .002 & .000 & .001 & .000 & .000 & .000 & .001 & .000 & .000 \\
\hline
\end{tabular}

C1-C13: Extent to which clinical sites provided opportunities

P1-P10: Extent to which mentors trained students in clinical skills

$\mathrm{P}=p$ value

recognized only as part of the institutional clinical experience. As a result, students may have been less appreciative of whatever patient care opportunity their mentors were able to offer, if it did not reach their expectations for engaging in direct patient care in clinical settings. This is evident in their opinions when students were unsatisfied for not being given opportunities to participate in pharmaceutical care and various clinical pharmacy patient care activities even when their clinical sites do provide such opportunities.

Despite ranking their clinical experiences as moderate, more than a third of students said that they did not receive adequate opportunity to hone pharmaceutical care skills and were unable to discuss barriers to pharmaceutical care related issues. Further, the objectives of developing effective relationships with patients, documenting their interventions for the identified drug-related problems, access to patient records were recorded as "did not occur" by more than a third of the students. Students reported that their mentors did not encourage them to participate in ward rounds, enhance communication skills, nor resolve drug-related problems. These responses suggest that activities related to PC skills offered by mentors are very minimal, and urgent emphasis is required to improve the quality of learning by developing more sophisticated mentor-student interaction, providing clinically skilled mentors to participate in ward rounds, and encouraging practice-friendly health care settings. These notions also have been proposed elsewhere in the literature. ${ }^{9,10}$

Pharmaceutical care in the wards is a multifaceted process that involves identifying, preventing, and resolving drug therapy problems. In addition, delivery of proper 


\section{American Journal of Pharmaceutical Education 2017; 81 (6) Article 109.}

pharmaceutical services such as obtaining patient history, evaluating laboratory data, and reviewing patient records is also associated with this process. ${ }^{11}$ PharmDs also should provide patient education and therapeutic follow-up to assess the desired outcome, with documentation of patient profiles presented in a standard format. In this study, the most common types of drug therapy problems observed by the students during their clinical rotations were unnecessary drug therapy $(78.2 \%)$, followed by adverse drug reactions $(39.1 \%)$ and non-adherence (35.2\%).

When students were asked how well their mentors taught clinical skills, more than half indicated that their clinical rotation experiences could have been better organized. Many felt that their mentors did not provide them adequate orientation, did not engage them in all mandatory activities, did not meet them sufficiently to review their work, only moderately encouraged their problem-solving skills and discussed the drug-related problems at the bedside. Further, a large number of students said that their mentors were not available in wards to answer questions and provide effective patient-centered education. The activities deemed necessary in the PharmD curriculum are appropriate; the role of the mentor is to provide patientcentered education at the bedside by discussing drugrelated issues with the students and collaborating with other health care professionals to be good role models. ${ }^{12}$ Further, role-modeling is thought to be a way for mentors to show their enthusiasm and commitment to their roles. Thus, mentors can motivate students by showing them how their learning activities relate to their future professional responsibilities. Such experiences set the stage for successful professional growth of the students through information, guidance, and regular constructive feedback. ${ }^{13}$

Although this study showed that majority of PharmD students cared about patient relationships, most colleges offering the PharmD program are run by private organizations that do not have their own hospitals. Hence, students may not get adequate clinical exposure, which is an essential component for nurturing competent clinical pharmacists. In fact, pharmaceutical care is not widely practiced in India, and it is important to observe how these students are implementing pharmaceutical care services in their respective hospitals and other practice sites. These efforts will be helpful for students to identify specific barriers and boost their professional image by improving care delivery in their clinical sites. Engaging mentors to practice pharmaceutical care and demonstrate the entire patient care process from initial assessment through documentation to follow-up evaluation in various clinical wards may help students understand the responsibilities and realities of clinical pharmacy practice.
This study highlighted the experiences of PharmD students and their perceptions about their mentors. Despite the students' commitment and enthusiasm, there is a need for mentors to develop and deliver an effective patient-centered educational program within the realities of clinical pharmacy practice. Further, timely evaluations of the mentors by the students can provide evidence about the program's performance.

\section{Limitations}

We used a quantitative cross-sectional study method to assess the clinical experiences of senior PharmD students and the training provided by their mentors to reduce selection bias. However, the study is not without limitations. More than $90 \%$ of the participants were from south Indian colleges, and the results might not be generalized to other pharmacy schools and colleges in India. In addition, data presented here is self-reported, and some of the respondents may provide extreme responses as compared to others, due to their motivations and beliefs, and might be subject to recall bias.

\section{CONCLUSION}

The results of this study showed that $38 \%$ of the current PharmD students were least satisfied with the clinical training program and identified deficiencies in its quality and reliability. One-third of the students expressed that their clinical sites did not provide them an opportunity to hone pharmaceutical care skills, and more than $40 \%$ stated that their mentors were not available in the wards and did not provide patient-centered education. Experimental evaluation of mentor competencies and obtaining student feedback on clinically oriented learning outcomes periodically during their clinical rotations can explore more authentic underlying epistemology of PharmD clinical training program. Mentors should invest more time in clinical sites to provide adequate practice-based clinical training and patient-centered education for the PharmD students in India. The views of the students may give valuable insight to the senior administrators of the pharmacy council. The academic institutions offering this program can take initiatives through one-on-one interviews and focus group discussions with students and mentors to identify specific solutions for their problems.

\section{ACKNOWLEDGMENTS}

The findings of this research work were presented during the 2016 American Colleges of Clinical Pharmacy (ACCP) virtual poster symposium and the abstract was published in Pharmacotherapy, 2016;36(7):e90. 


\section{American Journal of Pharmaceutical Education 2017; 81 (6) Article 109.}

\section{REFERENCES}

1. Basak SC, Sathyanarayana D. Pharmacy education in India. Am J Pharm Educ. 2010;74(4):Article 68.

2. Parthasarathi G, Ramesh M, Nyfort-Hansen K, Nagavi BG. Clinical pharmacy in a South Indian teaching hospital. Ann

Pharmacother. 2002;36(5):927-932.

3. The Gazette of India, No. 19, May 10-May 16, 2008, Part III-Section

4. http://www.pci.nic.in/. Accessed April 20, 2015.

4. Mateti UV, Balkrishnan R, Laddha A, Sharma S, Nagappa AN. Activities of PharmD students in Indian hospital. Pharma Rev.

2011;7:133-134

5. The Gazette of India, No. 19, May 10-May 16, 2008, Part II-Pages 8-9. http://www.pci.nic.in/. Accessed April 20, 2015.

6. Kassam R. Students' and preceptor' experiences and perceptions of a newly developed community pharmacy pharmaceutical care clerkship. Pharm Educ. 2006;6(3):179-188.
7. Srikanth B A, Ahmad A, Reddy RK, Balkrishnan R, Nagappa AN. Acceptance of doctor of pharmacy in India: A survey-based study. Arch Pharma Pract 2013;4:93-7.

8. Burke JM, Miller WA, Spencer AP, et al. Clinical pharmacist competencies. Pharmacotherapy. 2008;28(6):806-815.

9. Ahmad A, Srikanth BA, Patel I. Indian PharmD: should it be pursued? Arch Pharm Pract. 2014;5(2):97-98.

10. Wilbur K. Summative assessment in a doctor of pharmacy program: a critical insight. Adv Med Educ Pract. 2015;6:119-126. 11. Schommer JC, Cable GL. Current status of pharmaceutical care practice: strategies for education. Am J Pharm Educ. 1996;60(1):36-42. 12. Hajj MS El, Hammad AS, Afifi HM. Pharmacy students' attitudes toward pharmaceutical care in Qatar. Ther Clin Risk Manag. 2014;10:121-129.

13. Fuller K, Maniscalco-Feichtl M, Droege M. The role of the mentor in retaining junior pharmacy faculty members. Am J Pharm Educ. 2008;72(2):Article 41. 